\title{
Enhancement of Gain of Rectangular Micro Strip Antenna Using Multilayer Multidielectric Structure
}

\author{
Kharade A.R., Patil V.P., \\ Pulraj Electronics pvt. Ltd., Mumbai. India \\ Smt. Indira Gandhi College of Engineering, New Mumbai, India
}

\begin{abstract}
In rapidly developing market in personal communication systems (PCS), mobile satellite communications, direct broadband television (DBS) wireless local area networks (WLANs) suggest that demand for Microstrip antennas and array will increase even further. In this paper the gain of microstrip patch antenna is enhanced by using covered dielectric layer which is separated from feed patch by air as an another dielectric. Here two patches, one feed patch and one parasitic patch are used to enhance the gain and bandwidth and whole structure resonates at their resultant frequency which is in the ISM band. Air is used as dielectric between feed patch and ground plane as well as between feed patch and parasitic patch. The dimensions of feed patch are adjusted to achieve desired resonant frequency. In this microstrip antenna the coaxial probe feed technique is used for its simplicity. This antenna structure is simulated using zeland IE3D software package and effects of physical parameters are investigated. This work leads to conclusion that directivity, bandwidth and gain of microstrip antenna can be increased by covered dielectric and multidielectric structure with parasitic patch. The gain is found as 13.4 dbi and bandwidth as $220 \mathrm{MHz}$ which is higher as compare to conventional rectangular patch antenna.
\end{abstract}

Keywords: Gain, Directivity, Rectangular Microstip Antenna, Ie3d, VSWR.

\section{INTRODUCTION}

An MICROSTRIP ANTENNA (MSA) [1] in its simplest form consists of a radiating patch on one side of a dielectric substrate and a ground plane on the other side. The top view and side views of a rectangular MSA (RMSA) are shown in Figure-1and 2.It has dimensions of $\mathrm{W}$ as width, $\mathrm{L}$ as length and $\mathrm{h}$ as height.

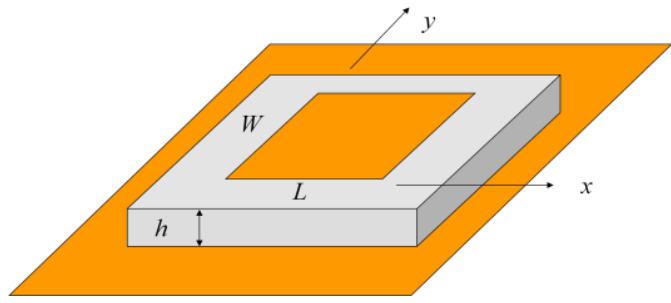

Figure-1: The top view of a rectangular MSA

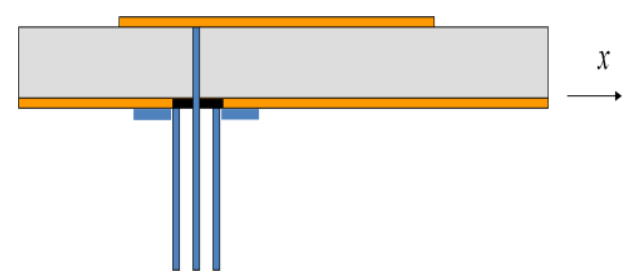

Figure-2: side view of patch antenna showing probe feed

However, other shapes, such as the square, circular, triangular, semicircular, sectoral, and annular ring shapes are also used. Microstrip antennas are popular for their attractive features such as low profile, low weight, low cost, ease of fabrication and integration with RF devices. The major disadvantages of Microstrip antennas are lower gain and very narrow bandwidth [2, 3]. Microstrip patch antenna consists of a dielectric substrate, with a ground plane on the other side. Due to its advantages such as low weight, low profile planar configuration, low fabrication costs and capability to integrate with microwave integrated circuits technology, the microstrip patch antenna is very well suited for applications such as wireless communications system, cellular phones, pagers, Radar systems and satellite communications systems [1,4].

The gain and directivity is the issue in fixed wireless local area network (WLAN) application where antenna of high gain and directivity is required. The gain can be increased by using the microstrip antenna array structure but this again increases the size. Hence the gain of microstrip antenna (MSA) is increased by slightly increasing the dimensions of patch antenna and multilayer structure with covered dielectric [5]. The MSA also should have good bandwidth and gain, and for this two patch technique called feed patch and parasitic patch are used. The resonant frequency of patch antenna is the function of the length of patch. The two patches have different length so their resonant frequencies are also different. Whole stricture resonates at their resultant of resonant frequencies. This increases the bandwidth and gain of MSA. Here FR4 dielectric material is used for its low cost and ease of availability. 
The paper is organized as follows: section 2 presents the brief literature survey about microstrip antenna and gain enhancement techniques. The structure and dimensions of the proposed antenna is presented in section 3 followed by the result and analysis of the simulated antenna in section 4 . Finally, section 5 provides the conclusion. Results are based on an antenna simulation software package IE3D.

\section{Previous Related Work}

Microstrip patch antennas have several well-known advantages, such as low profile, low cost, light weight, ease of fabrication and conformity [21, 24]. However, the microstrip antenna inherently has a low gain and a narrow bandwidth. To overcome its inherent limitation of narrow impedance bandwidth and low gain, many techniques have been suggested e.g., for probe fed stacked antenna, microstrip patch antennas on electrically thick substrate, slotted patch antenna and stacked shorted patches have been proposed and investigated [22].

The microstrip antenna concept dates back about 26 years to work in the U.S.A. by Deschamps [13] and in France by Gutton and Baissinot [6].Shortly thereafter, Lewin investigated radiation from stripline discontinuities. Additional studies were undertaken in the late 1960's by Kaloi, who studied basic rectangular and square configurations. However, other than the original Deschamps report, work was not reported in the literature until the early 1970's, when a conducting strip radiator separated from a ground plane by a dielectric substrate was described by Byron. This half wavelength wide and several wavelength long strip was fed by coaxial connections at periodic intervals along both radiating edges, and was used as an array for Project Camel. Shortly thereafter, a microstrip element was patented by Munson [7] and data on basic rectangular and circular microstrip patches were published by Howell. Weinschel developed several microstrip geometries for use with cylindrical S band arrays on rockets. Sanford showed that the microstrip element could be used in conformal array designs for L band communication from KC-135aircraft to the ATS-6 satellite. Additional work on basic microstrip patch elements was reported in 1975 by Garvin et al, Howell, Weinschel and Janes and Wilson. The early work by Munson on the development of microstrip antennas for use as low profile flush mounted antennas on rockets and missiles showed that this was a practical concept for use in many antenna system problems and thereby gave birth to the new antenna industry.

Extensive researches have been conducted to increase gain of microstrip patch antenna. In a resonance gain method [8-10], layers of dielectric are stacked above the patch. For a three-layer electromagnetically (EM) coupled structure, an air layer is often used between a substrate and a superstrate [11,12]. The patch is etched on top surface of a grounded substrate, and a coupled patch is on top [11] or bottom [12] surface of the superstrate. It was reported that gain of the patch antenna can be increased by tuning thickness of the air layer. In [11], the spacing is between $0: 31$, and 0.37 , In [12], the spacing is approximately one half free space wavelengths. Gain enhancement is demonstrated only for linearly polarized antenna.

In general, the impedance bandwidth of a patch antenna is proportional to the antenna volume, measured in wavelengths. However, by using two stacked patches with the walls at the edges between the two patches, one can obtain enhanced impedance band width. There has recently been considerable interest in the two layer probe fed patch antenna consisting of a driven patch in the bottom and a parasitic patch [23]. By stacking a parasitic patch High Gain Microstrip Patch Antenna 188 on a Microstrip patch antenna, the antenna with high gain or wide bandwidth can be realized [18]. These characteristics of stacked microstrip antenna depend on the distance between a fed patch and a parasitic patch. When the distance is about $0.1 \lambda$ (wavelength), the stacked microstrip antenna has a wide bandwidth [17].

Many broadband and gain enhancement techniques for microstrip antennas have been reported [13, 14], and to overcome the disadvantage of low gain, some papers have proposed gain enhancement methods using multiple superstrates $[15,16]$. However, the presence of superstrates above an antenna may adversely affect the antenna's basic performance characteristics, such as gain, radiation resistance, and efficiency. For this reason, it is important to analyze superstrate effects, so adequate superstrate parameters can be chosen to enhance gain and radiation efficiency. It has been reported that high gain can be achieved if the substrate and superstrate layers are used appropriately [15].

\subsection{Proposed structure}

\section{Proposed Methodology}

The dimensions of this MSA are designed for the resonant frequency of 5.8GHz. The feed patch is set at $2 \mathrm{~mm}$ height above ground plane and parasitic patch at height of $\lambda / 2$ above feed patch. The FR4 substrate is on parasitic patch with thickness of $1.6 \mathrm{~mm}$. Air is used as dielectric between ground plane and feed patch as well as between feed patch and parasitic patch. This is also called as space fed MSA and shown in Fig 3. Top parasitic patch is mounted using foam material which is having dielectric constant equal to air and acts as supporting to parasitic patch and top substrate. 


\subsection{Choice of Substrate}

Choosing a substrate is as crucial as the design itself. The substrate itself is part of the antenna and contributes significantly to its radiative properties. Many different factors are considered in choosing a substrate such as dielectric constant, thickness, stiffness as well as loss tangent. The dielectric constant should be as low as possible to encourage fringing and hence radiation. A thicker substrate should also be chosen since it increases the impedance bandwidth. However, using a thick substrate would incur a loss in accuracy since most microstrip antenna models use a thin substrate approximation in the analysis. Substrates which are lossy at higher frequencies should not be used for obvious reasons. The choice of a stiff or soft board basically depends on the application at hand. In this paper FR4 is selected as the dielectric material having dielectric constant as 1.

\subsection{Input Impedance Matching}

Impedance matching is critical in microstrip antennas since the bandwidth of the antenna depends upon it. Besides this, a poor match results in lower efficiency also. Line fed rectangular patches may be fed from the radiating or the non-radiating edge. To find an impedance match along the non-radiating edge we may use the Transmission Line Model. The input impedance along the non-radiating edge is lowest at the centre since two equally high impedances at the two ends are transformed into a low value at the centre and connected in parallel. Matching along the edge is also symmetrical about the mid-point of the length.

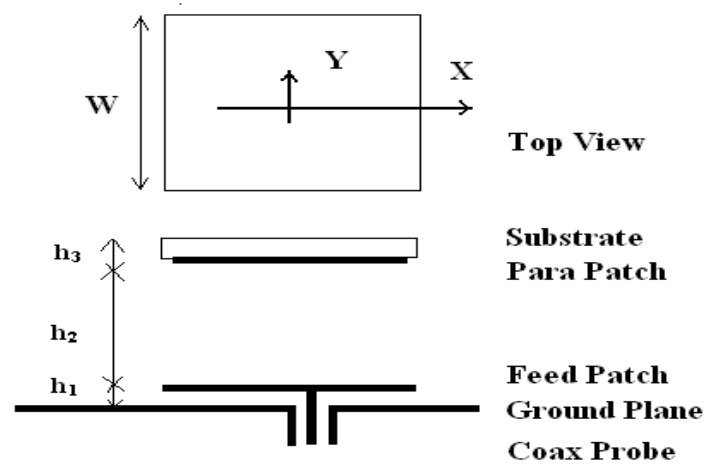

Fig.3 Space Fed MSA

Coaxial probe feed technique is used for its ease of feed. Top substrate is FR4 material acts as protective cover to parasitic patch. Air acts as low dielectric material which helps to increase directivity. Parasitic patch is kept at $\lambda / 2$ height from the feed patch. The patch dimensions are designed using basic patch antenna design [19].

\section{Patch width:}

Patch length:

$$
W=\frac{c}{2 f_{0} \sqrt{\left(\varepsilon_{r}+1\right) / 2}}
$$

$$
L=\frac{c}{2 f_{0} \sqrt{\varepsilon_{\text {reff }}}}
$$

Where $\varepsilon_{\mathbf{r}}$ is dielectric constant and Ereff effective dielectric constant of material. The MSA structure is called multidielectric because more than one dielectric material is used here. Complete specifications are given in Table 1.

Table 1: Parameters of multidielectric microstrip patch antenna $\left(\mathrm{f}_{\mathbf{0}}=\mathbf{5 . 8 G H z}\right)$

\begin{tabular}{|l|l|l|}
\hline S.No. & Layer Geometry & Dimensions \\
\hline 1 & Top substrate & $\varepsilon_{\mathrm{r} 3}=4.4, \mathrm{~h}_{3}=2$ \\
\hline 2 & parasitic patch & $\mathrm{W}_{\mathrm{P}}=22 \mathrm{~mm}, \mathrm{~L}_{\mathrm{P}}=16 \mathrm{~mm}$ \\
\hline 3 & Air gap 2 & $\varepsilon_{\mathrm{r} 2}=1 \quad \mathrm{~h}_{2}=26 \mathrm{~mm}$ \\
\hline 4 & Feed patch & $\mathrm{W}_{\mathrm{F}}=24 \mathrm{~mm} \mathrm{~L}_{\mathrm{F}}=22 \mathrm{~mm}$ \\
\hline 5 & Air gap 1 & $\varepsilon_{\mathrm{r} 1}=1 \quad \mathrm{~h}_{1}=2 \mathrm{~mm}$ \\
\hline 6 & Ground plane & Aluminum \\
\hline 7 & Feed & $\begin{array}{l}50 \Omega, S M A \text { probe } \\
\mathrm{X}_{\mathrm{f}}=2.8 \mathrm{~mm} \quad \mathrm{Y}_{\mathrm{f}}=0 \mathrm{~mm}\end{array}$ \\
\hline
\end{tabular}




\section{Analysis and Results}

The result of designed and fabricated rectangular microstrip antenna is analyzed as described below. Simulation is done using IE3D simulation software package [20]. The photograph of fabricated microstrip antenna along with test set up on vector network analyzer is shown in fig 4 .

The gain and directivity is the function of patch width and dielectric constant [19]. For normal patch antenna with single substrate, the directive gain is 6-8 dB. For given dimensions, the MSA structure is simulated using IE3D simulation software for the frequency range of $5 \mathrm{GHz}$ to $6.5 \mathrm{GHz}$ and field gain is plotted and shown in fig. 5. The probe is fed at $X_{\mathrm{f}}=3.8 \mathrm{~mm}$ and $\mathrm{Y}_{\mathrm{f}}=0$. It is observed that this patch antenna has gain of $13.4 \mathrm{dBi}$ which is higher than normal patch antenna. This patch antenna resonates at $5.8 \mathrm{GHz}$ which is in ISM band. Air gap between ground and feed patch helps to increase gain.

The table 2 shows the comparative results for return loss, impedance. VSWR and directivity, efficiency and it is seen that the results of simulated antenna structure and fabricated structure are almost similar. Directive gain of conventional patch antenna is around 6 to $8 \mathrm{db}$ and field gain of our designed antenna is $13.4 \mathrm{dbi}$ and for fabricated antenna field gain is $13.0 \mathrm{dbi}$. That means, the gain is higher than that of conventional rectangular patch antenna. As shown in fig 7, the return loss of simulated antenna is $-24 \mathrm{db}$ whereas that of fabricated antenna is $-22 \mathrm{db}$ as shown in fig 6 . The impedance at resonance for both simulated and fabricated antenna is found same i.e. $50 \mathrm{ohms}$. VSWR of designed and fabricated antenna is almost similar and is equal to 1 as shown in fig 8 and 9 . The radiation pattern of designed is shown in fig 11 which shows that it has narrow beam width. As shown in fig 10, the antenna efficiency of the designed antenna is $88 \%$ and radiation efficiency is stable between 85 to $91 \%$, whereas the antenna efficiency of fabricated antenna is found to be $86 \%$. The bandwidth of designed antenna is $220 \mathrm{MHZ}$ and that of fabricated antenna is $210 \mathrm{MHZ}$.

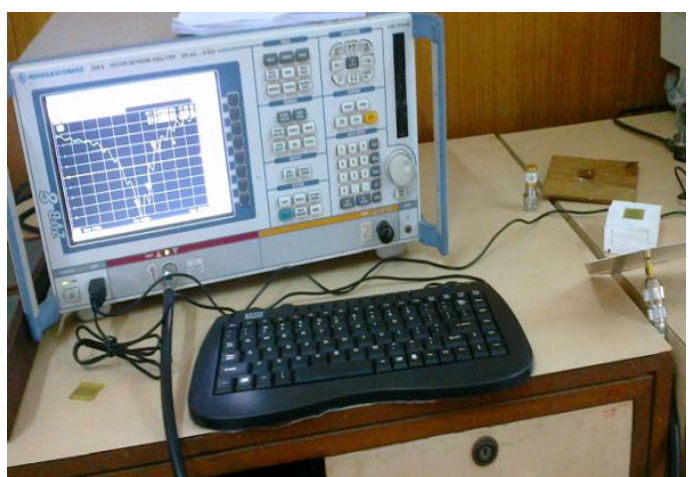

Fig.4-Photograph of fabricated microstrip antenna.

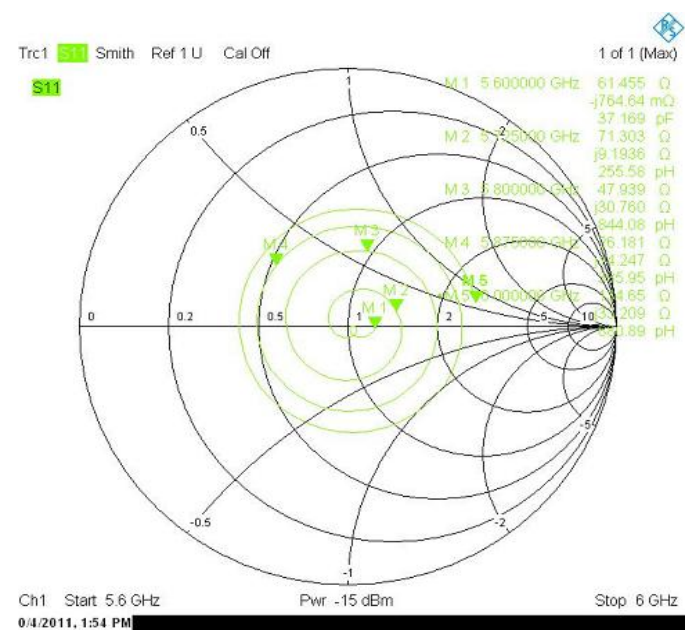

Fig 6- Return loss of fabricated microstrip antenna

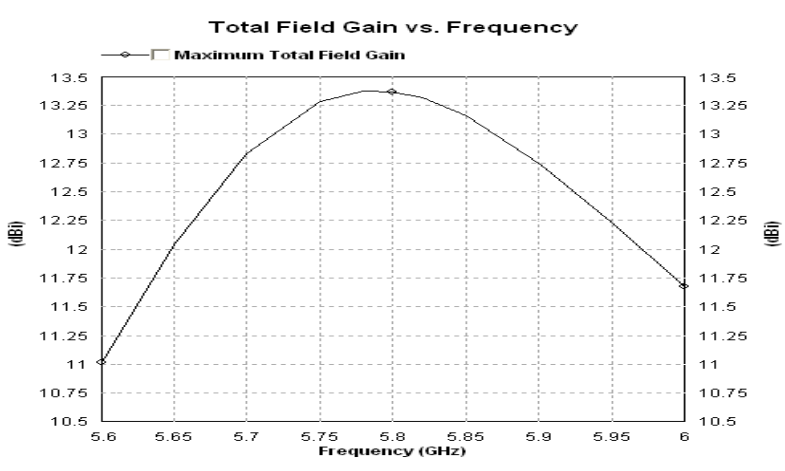

Fig 5- Gain of designed microstrip antenna.

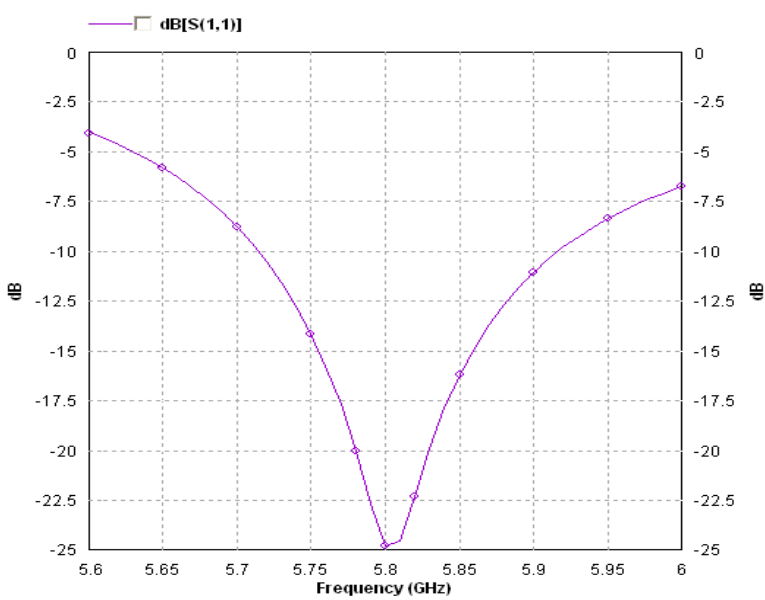

Fig 7- Return loss of designed microstrip antenna 


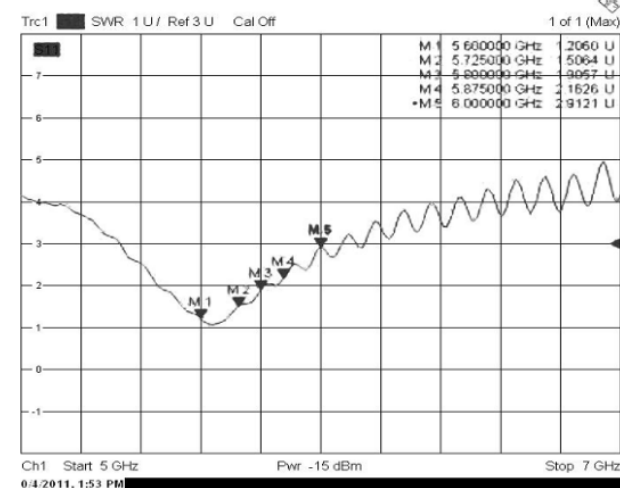

Fig 8- VSWR of fabricated microstrip antenna

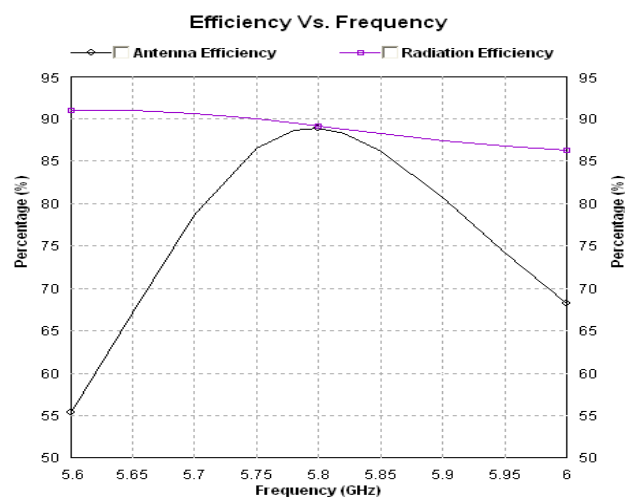

Fig 10-Efficiency of designed microstrip antenna.

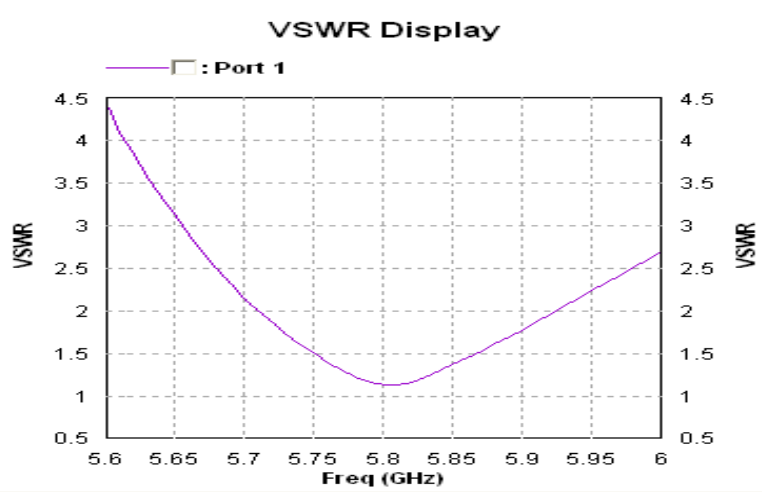

Fig 9-VSWR of designed microstrip antenna.

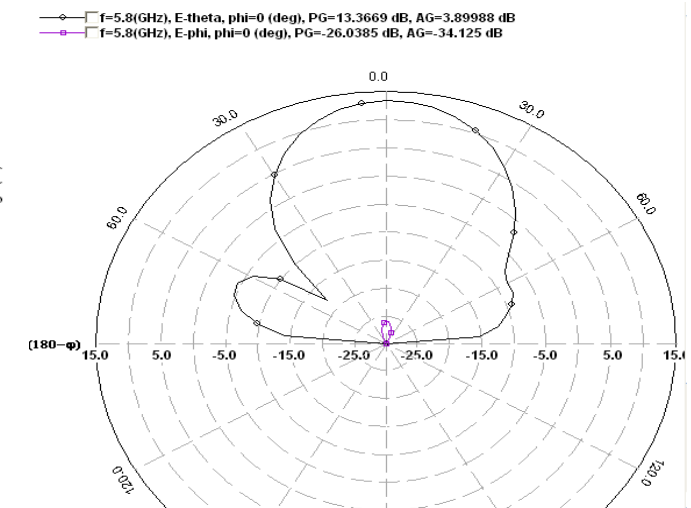

Fig 11- Radiation pattern of designed microstrip antenna

Table 2- Comparison of Simulated and Fabricated antenna Results

\begin{tabular}{|l|l|c|c|}
\hline S.No. & Parameters & $\begin{array}{c}\text { Designed } \\
\text { Antenna }\end{array}$ & Fabricated Antenna \\
\hline 1 & VSWR & 1.05 & 1.0 \\
\hline 2 & Gain & $13.4 \mathrm{dbi}$ & $13.0 \mathrm{dbi}$ \\
\hline 3 & Antenna efficiency & $88 \%$ & $86 \%$ \\
\hline 4 & Return Loss & $-24 \mathrm{db}$ & $-22 \mathrm{db}$ \\
\hline 5 & Impedance & $50 \mathrm{ohm}$ & $50 \mathrm{ohm}$ \\
\hline 6 & Bandwidth & $220 \mathrm{MHz}$ & $210 \mathrm{MHz}$ \\
\hline
\end{tabular}

\section{Conclusion}

Gain and Directivity can be increased by using multilayer dielectric covered layer structure and increasing patch dimensions however bandwidth and gain can be increased by using parasitic patch and air gap between ground plane and feed patch. This work leads to the conclusion that high directive broadband antenna with high gain are designed using multilayer multidielectric antenna. It is observed that the gain of designed antenna is $13.4 \mathrm{dbi}$ and bandwidth is $220 \mathrm{MHz}$ which is higher than conventional rectangular patch antenna. Other antenna parameters like VSWR, efficiency, return loss, impedance are measured for designed and fabricated antenna and observed that results are comparatively almost same. Further gain and directivity can be increased by using more dielectric substrate and proper air gap spacing. Such high directive antennas are useful in fixed wireless local area network (WLAN).

\section{References}

[1] W.L. Stutzman and G.A. Thiele, Antenna Theory and Design, 2nd ed. New York: Wiley, 1998.

[2] Thomas A. Milligan. 2nd Ed. Modern antenna design. pp. 318-354.

[3] A.K Bhattacharjee, S.R Bhadra, D.R. Pooddar and S.K. Chowdhury. 1989. Equivalence of impedance and radiation properties of square and circular microstrip patches antennas. IEE Proc. 136 (Pt, H, no. 4): 338-342.

[4] C.A. Balanis, Antenna Theory, 2nd ed. New York: John Wiley \& Sons, Inc., 1997.

[5] Kaymaram and L. Shafai, "Enhancement of microstrip antenna directivity using double-superstrate configurations", Electrical and Computer Engineering, Canadian Journal of vol. 32, issue 2, spring 2007, pages: 77-82

[6] H. Gutton and G. Baissinot, "Flat aerial for ultra high frequencies", French patent No. 703113, 1955

[7] R. E. Munson, "Single slot cavity antennas assembly", U.S. patent No. 3713 162, January 23, 1973. 
[8] Jackson, D. R. and N. G. Alexopoulos, IGain enhancement methods for printed circuit antenna," IEEE Tansactions on Antennas and Propagation, Vol. 33, 976\{987, Sep. 1985.

[9] Yang, H. Y. and N. G. Alexopoulos, IGain enhancement methods for printed circuit antennas through multiple superstrates," IEEE Tansactions on Antennas and Propagation, Vol. 35, No. 7, 860-863, Jul. 1987.

[10]. Shen, X.-H., G. A. E. Vandenbosch, and A. R. Van de Capelle, IStudy of gain enhancement method for microstrip antenna using moment method," IEEE Tansactions on Antennas andPropagation, Vol. 43, No. 3, 227-231, Mar. 1995.

[11]. Lee, R. Q., K. F. Lee, and J. Bobinchak, "Characteristics of a two-layer electromagnetically coupled rectangular patch antenna," Electronics Letters, Vol. 23, No. 20, 1301-1302, 1987.

[12]. Nishiyama, E., M. Aikawa, and S. Egashira, "Stacked microstrip antenna for high-gain and wideband," IEE Proc. Microw.Antennas Propag., Vol. 151, No. 2, 143-148, Apr. 2004.

[13] A. Sabban, “A New Broadband Stacked Two-layer Microstrip Antenna,” IEEE AP-S Int. Symp. Digest, vol. 21, May 1983, pp. 6366.

[14] Jang Y. W., "Wide-Band T-Shaped Microstrip-Fed Twin-Slot Array Antenna," ETRI J., vol.23, no.1, Mar. 2001, pp.33-38

[15] D. R. Jackson and N. G. Alexopoulos, "Gain Enhancement Methods for Printed Circuit Antennas," IEEE Trans. Antennas Propagat., vol. 33, no. 9, Sept. 1985, pp.976-987.

[16] H. Y. Yang and N. G. Alexopoulos, "Gain Enhancement Methods for Printed Circuit Antennas through Multiple Superstrates," IEEE Trans. Antennas Propagat., vol. 35, no. 7, July 1987, pp.860-863.

[17] Araki, K., H., Ueda, and M., Takahashi, 1986. "Numerical analysis of circular disk microstrip antenna with parasitic elements", IEEE Transactions on Antennas and Propagation 34(12), pp. 1390-1394.

[18] Egashira, S. and E., Nishiyama, 1996. "Stacked microstrip antenna with wide bandwidth and high gain", IEEE Transactions on Antennas and Propagation 44, pp. 1533-1534.

[19] Girish Kumar and K. P. Ray, "Broadband Microstrip Antennas", Aptech House, Boston, London.

[20] Zeland IE3D software and its tutorial.

[21] He, W., R., Jin, and J., Geng, 2008. "E-Shape patch with wideband and circular polarization for millimeter-wave communication", IEEE Transactions on Antennas and Propagation 56(3), pp.893-895.

[22] Pozar, D.M. and D.H., Schaubert, 1995. "Microstrip antennas, the analysis and design ofmicrostrip antennas and arrays", New York: IEEE press

[23] Pozar, D.M., 1992. "Microstrip Antennas", Proceeding IEEE 80.

[24] Wong, K.L. and W.H., Hsu, 2001. "A broadband rectangular patch antenna with a pair of wide slits", IEEE Transactions on Antennas and Propagation 49, pp. 1345-1347.

[25] Zhang, Y.P. and J.J., Wang, 2006. "Theory and analysis of differentially-driven microstrip antennas", IEEE Transactions on Antennas and Propagation 54(4), pp.1092-1099.

\section{AUTHORS}

AUTHOR 1: Er. Kharade A.R. is working as a System Engineer in Pulraj Electronics pvt. Ltd., Mumbai. India. $\mathrm{He}$ is graduate in B.E. and post graduate in M.E (ELECTRONICS ENGINEERING). He is having 16 years of experience in teaching in engineering colleges and in industry. His area of research is in antenna and wave propagation and microwave engineering.

AUTHOR 2: Er. Patil V.P. is working as a faculty member in Electronics and Telecommunication Engineering department in smt. Indira Gandhi college of Engineering New Mumbai. He is graduate in B.E. and post graduate in M.TECH (ELECTRONICS DESIGN AND TECHNOLOGY). He is having 25 years of experience in teaching in engineering colleges. His area of research is in computer communication networking and microwave engineering. 